\title{
ESTIMATION OF GENETIC COMPONENTS FOR PLANT GROWTH AND PHYSIOLOGICAL TRAITS OF WHEAT (Triticum aestivum L) UNDER NORMAL AND STRESS CONDITIONS
}

\author{
M.K. Naeem, M. Ahmed, S. Noreen, M.K.N. Shah and M.S. Iqbal"1 \\ Pir Mehar Ali Shah Arid Agriculture University, Rawalpindi, Pakistan
}

\begin{abstract}
This study was conducted to investigate the genetic variability of plant growth and physiological characters in thirty wheat genotypes under normal and drought stress conditions. Selection of important plant growth and physiological traits are essential component for wheat yield improvement. For this purpose, an experiment was conducted in the glasshouse during 2012-13 to estimate the extent of genetic components viz., genetic variance, coefficient of variability and broad sense heritability for plant growth and physiological traits under normal and drought stress conditions. Higher genetic variance was observed between the genotypes for the cell membrane stability, excised leaf water loss, relative water content, proline, sugar and glycine betain under both conditions. This suggested that these indices can be used as direct selection criteria for wheat improvement. While excised leaf water loss and fresh root weight revealed the least variability for GCV and PCV correspond to high heritability under stress condition. Hence, these traits can be used as indirect selection criteria under stress condition.
\end{abstract}

Keywords: Drought, Genetic variability, Osmotic adjustment, Wheat

\section{INTRODUCTION}

Wheat, ranking second among cereals, is important staple food crop and it provides $21 \%$ of the food calories and $20 \%$ of the protein in human nutrition to more than 3.5 billion people in 94 countries (Braun et al., 2010). Approximately 21\% of the food relies on the wheat, which cultivated on 200 million hectares worldwide (FAO, 2010). The global demand and consumption of agricultural crops for food urges food security due to burgeoning population. In rural areas of Pakistan, wheat is the important source of income. The wheat area, production and yield are 8693

\footnotetext{
* Corresponding author email: shahidkooria@gmail.com

${ }^{1}$ Ayub Agricultural Research Institute, Faisalabad, Pakistan

Received: $30 \cdot 10.2014$
} 
thousand hectares, 24231 thousand tons and $2787 \mathrm{~kg} \mathrm{ha}^{-1}$, respectively during 201213 (GOP, 2012-13). The yield gap is mainly due to erratic rainfalls, water scarcity in rainfed areas and high temperature. Pfeiffer et al. (2005) reported that drought affects the $50 \%$ of wheat area worldwide. Under such moisture stress conditions development of rapid, effective screening method is a major challenge for plant breeders (Khan et al., 2013; Mahmood et al., 2013; Subhani et al., 2012). Germplasm improvement for drought can be accomplished significantly through the use of physiological interventions in breeding (Reynolds and Trethowan, 2007).

Physiological traits gave better understanding of plants response against drought and insight into metabolic pathways at molecular level (Naeem et al., 2013). Plants adopted drought tolerance via three major physiological domains: a) maintenance high plant water status under drought stress; b) maintenance of plant function at low plant water status; c) recovery of plant water status and plant function after stress. Among the first physiological domain, osmotic adjustment, proline, sugar, glycine betain, leaf succulence while from second physiological domain, relative water content, chlorophyll content and cell membrane stability are studied. Along with physiological traits, growth traits studied to access the drought impact on plant stature.

For developing suitable selection strategy, the knowledge of genetic variability present in the available wheat germplasm for growth and physiological traits is important (Noorka et al., 2009 and Rauf et al., 2013). Genetic improvement of wheat crop is mostly depend on the degree of genetic variability and the magnitude to which desirable traits are heritable (Ahmad et al., 2014; Hanif et al., 2013; Hassan et al., 2012; Mahmood et al., 2013; Zamurrud et al., 2013). This study provides the knowledge about the presence of variation in their genetic constitution and basis for effective selection. An attempt, therefore, was made in the present study to estimate the magnitude of genetic variance, coefficient of variability and heritability of growth and physiological traits by using 30 genotypes of wheat.

\section{MATERIAL AND METHODS}

An experiment was conducted for thirty wheat genotypes, developed by different research institutes for drought prone areas in Pakistan. This was conducted in glass-house of PMAS- Arid Agriculture University, Rawalpindi during 201213.Thirty wheat genotypes were sown in triplicate in Complete Randomized Design (CRD) in polythene bags $(12 \times 6$ inch size), which were filled by soil mixture having field soil, sand and farm yard manure in 3:1/2:1 proportions and maintained in glasshouse conditions i.e. $20 \pm 2^{\circ} \mathrm{C}$ temperature, under natural daylight. Two treatments namely control and drought stress was imposed. Eight seeds were sown in each bag and after germination seedlings were thinned to four. Drought stress was imposed by withholding water as done by Gusmao et al. (2012). 
Water stress was imposed at tillering stage and watering was interrupted for 15 days of stressed treatment pots as reported by Bajji (2001) and control treatment was watered normally. After fifteen days of stress, data of physiological traits including osmotic adjustment (OA), estimation of proline, glycine betaine (GB), sugar content, chlorophyll content (CC), relative water content (RWC), excised leaf water retention (ELWR), leaf succulence (LS) and cell membrane stability (CMS) were recorded. Similarly plant growth parameters i.e. shoot length (SL), root length (RL), fresh shoot weight (FRW), fresh root weight (FRW), total plant weight (TPW), dry shoot weight (DSW) and dry root weight (DRW) were determined. All physiological measurements and sampling for biochemical analysis were taken at 8:00am-11am.

Genetic components include genotypic variance $\left(\sigma_{\mathrm{g}}^{2}\right)$ and phenotypic variance $\left(\sigma_{p}^{2}\right)$ computed according to Kown and Torrie (1964), genotypic coefficient of variation $(\mathrm{GCV})$ and phenotypic coefficient of variation (PCV) were calculated method given by Burton. and Devane (1953) while broad sense heritability $\left(\mathrm{h}^{2}{ }_{\text {bs }}\right)$ analyzed according to Hanson et al. (1956).

\section{RESULTS AND DISCUSSION}

\section{Genotypic and Phenotypic Variability}

The genotypic variability $\left(\delta_{\mathrm{g}}^{2}\right)$ of seventeen traits ranged from 0.003 to 95.296 for normal grown and 0.001 to 621.323 for stressed plant. Similarly phenotypic variance $\left(\delta_{\mathrm{p}}^{2}\right)$ ranged from 0.01 to 250.765 under normal and 0.004 to 685.416 under stressed condition. This demonstrated that $t$ greater range of genotypic and phenotypic variability exists for all traits. Osmotic adjustment had least genotypic $(0.019)$ and phenotypic $(0.055)$ variance while cell membrane stability had maximum genotypic variability (111.665) and phenotypic variance (275.975). This result provided the evidence that greater variation exists among the genotypes for cell membrane stability. While cell membrane stability, excised leaf water loss, relative water content, proline, sugar and glycine betain under both conditions showed the highest genetic variability between the genotypes under normal and stress condition (Table 1).

Growth parameters and chlorophyll content among other physiological traits had greater genotypic variance for normal than drought stressed plants. Similar behavior also revealed by phenotypic variance of growth traits, chlorophyll content, relative water content and leaf succulence except other physiological traits. While fresh shoot weight revealed the maximum value for genotypic and phenotypic variance under normal than drought treated. These results provided the evidence that growth related traits are influenced much under normal condition. While all physiological traits except chlorophyll content revealed the maximum genotypic variance and phenotypic variance under stress condition. This result convinced that most of physiological traits are activated and pronounced their effects when plants faced the drought stress condition. These observations are in agreement with findings 
of Khan et al. (2007) and Manggoel et al. (2012). Greater differences between genotypic $\left(\sigma_{g}^{2}\right)$ and phenotypic variances $\left(\sigma_{p}^{2}\right)$ gave evidence that these traits were greatly influenced by the environment. Like traits excised leaf water retention and relative water content under normal condition while proline and relative water content under drought stress revealed the greater differences among phenotypic and genotypic variance.

\section{Estimation of Coefficient of Variability}

The genotypic coefficient of variability for growth and physiological traits ranged from $5.966 \%$ to $25.127 \%$ under normal grown plants, while drought stressed plants ranged from $5.063 \%$ to $42.982 \%$. Under studied genotypes demonstrated the high level of genotypic coefficient of variability for ELWL and OA. This finding provides the evidence that these traits play an important role in genetic variation. Similarly the phenotypic coefficient of variability for growth and physiological traits ranged $11.481 \%$ to $34.524 \%$ under normal growth condition, while drought treated plants ranged from $9.576 \%$ to $44.246 \%$. High level of phenotypic coefficient of variability contributed to fresh root weight, excised leaf water loss, leaf succulence, proline, sugar, glycine betaine and osmotic adjustment in studied genotypes. This convinced that environmental factors suppress the expression of traits.

Higher phenotypic coefficient of variability for traits like osmotic adjustment, leaf succulence, glycine betaine, proline, sugar and relative water content than the genotypic coefficient of variability is observed. This revealed the obvious influence of environment on the expression of these traits. These finding corroborated the observations reported by Soleymanifard et al., 2012 and Sedeek et al., 2009. Fresh root weight and excised leaf water loss demonstrated the least difference between phenotypic coefficient of variability and genotypic coefficient of variability. Sedeek et al. (2009) were also observed the least difference between phenotypic and genotypic coefficient of variability. This revealed that most fraction of phenotypic coefficient of variation mostly contributed by the genetic components and least influenced by environmental factors. These traits might be genetically predominant and having ability for further improvement. Hence these variations can be exploited in wheat breeding program.

\section{Heritability estimates}

Heritability plays a predictive role in breeding programme, showing the reliability of phenotypes as a guide to its breeding value (Tazeen et al., 2009). Superior heritability values recorded, indicates the possibility of improvement in the traits. Estimates of heritability in broad sense ranged from $94.1 \%$ to $8.9 \%$ in normal, while in stress broad sense heritability ranged from $94.4 \%$ to $25 \%$. In normal growth condition, heritability was high for root length, fresh root weight, total weight and dry shoot weight. While in stress condition high for fresh root weight, total weight and excised leaf water retention prevailed among the studied genotypes. Cell membrane stability and osmotic adjustment demonstrated the moderate level of broad sense heritability. 
Higher broad sense heritability magnitude revealed that greater proportion of the entire variance was due to the greater genotypic variance influenced less by environmental factors therefore having high heritable variations. Such findings were suitable for reliable selection of traits, which are the key components for any crop improvement program (Thiyagarajan, 1990). The low broad sense heritability magnitude revealed traits under examination had lower genetic potentials. Kandic et al. (2009) suggested that the heritability of physiological traits is lower than the heritability of morphological traits. Similar trends were showed by relative water content and leaf succulence traits depicted lower heritability. This is due to the great contribution of the experimental error in the total phenotypic variability.

Least variation between phenotypic coefficient of variability and genotypic coefficient of variability correspond to high heritability were evaluated in different studies (Khan et al., 2007). The interpretation of results revealed that traits like fresh root weight and excised leaf water retention in stress environment have less difference between phenotypic coefficient of variability and genotypic coefficient of variability correspond to high heritability. Like fresh root weight in normal environment showed the difference 0.778 correspond to $94.1 \%$ heritability, in stress difference showed 1.35 correspond to $87.5 \% \mathrm{~h}^{2}{ }_{(\mathrm{bs})}$. While excised leaf water retention in stress environment depicted the 1.246 difference between phenotypic coefficient of variability and genotypic coefficient of variability correspond to $94.4 \%$ broad sense heritability. Traits having fewer differences between phenotypic coefficient of variability and genotypic coefficient of variability corresponding high heritability indicated that selection would be effective.

\section{CONCLUSION}

These results provided the evidence that growth related traits are influenced much under normal condition and had pronounced difference for $\sigma_{g}^{2}$ and $\sigma_{p}^{2}$. Proline and relative water content under drought stress condition demonstrated the greater differences among genotypic $\left(\sigma_{\mathrm{g}}^{2}\right)$ and phenotypic variances $\left(\sigma_{\mathrm{p}}^{2}\right)$ gave evidence that these traits were greatly influenced by the environment. Excised leaf water loss and fresh root weight showed least differences between GCV and PCV and corresponded to higher broad sense heritability, depicted these trait are genetically dominant and prevailing variations are heritable. This suggests that further improvement in these traits is possible.

\section{REFERENCES}

Ahmad, R., D. Ibrar, M.Y. Mirza, T. Mahmood, M.A. Khan, M.S. Iqbal and Ahmad, M 2014. Genetic Variability, Heritability and Genetic Advance in some genotypes of Linseed (Linum usitatisimum L.). Journal of Agricultural Research, 52 (1):43-52

Bajji, M., Lutts, S. and Kinet, J. 2001. Water deficit effects on solute contribution to osmotic adjustment as a function of leaf ageing in three durum wheat (Triticum durum Desf.) cultivars performing differently in arid conditions. Plant Science, 160: 669-681 
Braun, H.J., Atlin, G. and Payne, T. 2010. In: Reynolds, CRP. (ed.), Climate change and crop production, CABI, London, UK

Burton, G.M. and Devane, E.M. 1953. Estimating heritability in tall Fescue from replication clonal material. Agronomy Journal, 45: 478-481

FAO. 2010. Food and agricultural organization of the United Nations (FAO), FAO statistical database, 2010

GOP. 2012. Economic survey of Pakistan 2012-13. Economic Advisory Wing Finance Division, Islamabad

Gusmao, M., Siddique K.H.M., Flower K, Nesbitt H and Veneklaas E. J. 2012. Water deficit during the reproductive period of grass pea (Lathyr ussativus L.) reduced grain yield but maintained seed size. Journal of Plant Breeding and Crop Science, 198: 430-441

Hanif, R., Naeem-Ud-Din, Subhani A., Rabbani G, Tariq M, Iqbal M.S. and Koukab M. (2013) Performance Based Evaluation of Different Genotypes of Mungbean (Vigna Radiata) Under Rainfed Conditions of Chakwal. Journal of Agri-Food and Applied Sciences, 1(1): 13-15

Hanson, C.H., Robinson, H.F., and Comstock, R.E. 1956. Biometrical studies on yield in segregating population of Korean lespedesa. Agronomy Journal, 48: 268-272

Hassan S.M.F., M.S. Iqbal, G. Rabbani, Naeem-ud-Din and Shabbir, G. 2012. Genetic variability, heritability and genetic advance for yield and yield components in sunflower (Helianthus annuus L.). Electronic Journal of Plant Breeding, 3(1):707-710

Kandic, V., Dodig, D., Jovic, M., Nikolic, B. and Prodanovic, S. 2009. The importance of physiological traits in wheat breeding under irrigation and drought stress. Genetika, 41:11-20

Khan M.I, G. Shabbir, Z. Akram, M.K.N. Shah, M. Ansar and Iqbal, M.S. 2013. Character Association Studies of Seedling Traits in Different Wheat Genotypes under Moisture Stress Conditions. SABRAO Journal of Plant Breeding and Genetics, 45(3)

Khan, N.U., Hassan, G., Kumbhar, M.B., Parveen, A., Aiman, U., Ahmad W., Shah S.A. and Ahmad S. 2007. Gene action of seed traits and oil content in upland cotton $(G$. hirsutum). SABRAO Journal of Breeding and Genetics, 39: 17-30

Kwon, S.H. and Torrie, J.H. 1964. Heritability and inter-relationship among traits of two Soybean populations. Crop Science, 4:196-198

Mahmood A., M.A. Mian, M. Ihsan, M. Ijaz, G. Rabbani and Iqbal, M.S. 2013. Chakwal-50: A high yielding and disease resistant wheat variety for rainfed region. Journal of Animal and Plant Sciences, 23(3): 833-839

Manggoel, W., Uguru, M.I., Ndam, O.N. and Dasbak, M.A. 2012. Genetic variability, correlation and path coefficient analysis of some yield components of ten cowpea (Vigna unguiculata (L.) Walp) accessions. Journal of Plant Breeding and Crop Science, 4: $80-86$

Naeem, M.K., Rauf, S., Iqbal, H., Shah, M.K.N. and Mir A. 2013. In-silico studies of C3metabolic pathway proteins of wheat (Triticum aestivum). Bio Med Res. Int., Article ID 294759 
Noorka, I. R., I. Khaliq, Z. Akram and Iqbal, M.S. 2009. Inheritance studies of physio-genetic traits in spring wheat under normal and moisture stress environments. International Journal of Agriculture and Applied Sciences, 1(1): 29-34

Pfeiffer, S., Doris, S. and Dippner J.W. 2005. Effects of temperature and salinity on acetylcholinesterase activity, a common pollution biomarker, in Mytilus sp. From the south- western, Baltic Sea. Journal of Experimental Marine Biology and Ecology, 320(1):93-10

Rauf, Y., A. Subhani, M. Tariq, A. Mahmood and Iqbal, M.S. 2013. Study On Screening Of Wheat Genotypes for Drought Tolerance By Utilizing Drought Related Indices. SABRO Journal of Breeding and Genetics, 45 (2): 255-263

Reynolds, M.P and Trethowan, R.M .2007. Physiological interventions in breeding for adaptation to abiotic stress. Reynolds, M.P. and Trethowan, R.M. 2007. Physiological interventions in breeding for adaptation to abiotic stress. In: Spiertz JHJ, Struik PC, van Laar HH (eds) Scale and complexity in plant systems research, gene-plant-crop relations. Wageningen UR frontis series, 21: 129-146

Sedeek, S.E.M., Hammoud, S.A.A., Ammar, M.H and Metwally, T.F. 2009. Genetic variability, heritability, genetic advance and cluster analysis for some physiological traits and grain yield and its components in rice (Oryza sativa L.). Journal of Agricultural Research Kafer El-Sheikh University, 35:858-878

Soleymanifard, A., Naseriand, R. and Meysam, M. 2012. The study genetic variation and factor analysis for agronomic traits of Durum wheat genotypes using cluster analysis and path analysis under drought stress condition in western of Iran. International Research Journal of Applied and Basic Science, 3 (3): 479-485

Subhani A., M. Tariq, M.S. Jafar, R. Latif, M. Khan, M.S. Iqbal and Iqbal, M.S. 2012. Role of Soil Moisture in Fertilizer Use Efficiency for Rainfed Areas-A Review. Journal of Biology Agriculture and Healthcare, 2(11): 1-9

Tazeen, M., Nadia, K. and Farzana, N.N. 2009. Heritability, phenotypic correlation and path coefficient studies for some agronomic characters in synthetic elite lines of wheat. Journal of Food Agriculture and Environment, 7(3-4): 278-282

Thiyagarajan, K. 1990. Genetic variability in cowpea. Agricultural Science Digest, 10: 8-10

Zamurrad M, Tariq M, Shah FH, Subhani A, Ijaz M, Iqbal M.S and Koukab M (2013). Performance Based Evaluation of Groundnut Genotypes under Medium Rainfall Conditions of Chakwal. Journal of Agri-Food and Applied Sciences, 1 (1): 9-12 
Table 1. List of varieties/genotypes used in estimation of genetic components for plant growth and physiological traits of wheat (Ttriticum aestivum $\mathrm{L}$ ) under normal and stress conditions

\begin{tabular}{cccccccc}
\hline S. No. & Genotypes & S. No. & Genotypes & S. No. & Genotypes \\
\hline 1 & C-271 & 11 & LLR-14 & 21 & Punjab-96 \\
2 & C-273 & 12 & LLR-19 & 22 & Kohsar-95 \\
3 & WC-1 & 13 & LLR-29 & 23 & Lylpur-73 \\
4 & WC-3 & 14 & LLR-39 & 24 & Auqab-2000 \\
5 & WC-4 & 15 & Shahkar-95 & 25 & Sehar-06 \\
6 & WC-8 & 16 & Lasani-08 & 26 & Fsd-85 \\
7 & WC-22 & 17 & Blue-Silver & 27 & Pasban-90 \\
8 & WC-25 & 18 & MH-97 & 28 & Kohistan-97 \\
9 & LLR-4 & 19 & Maxi-Pak & 29 & AUR-0809 \\
10 & LLR-13 & 20 & Fsd-83 & 30 & Dhrabi \\
\hline
\end{tabular}


Table 2. Genetic variability parameters for seventeen traits in thirty wheat genotypes under normal and drought stress conditions

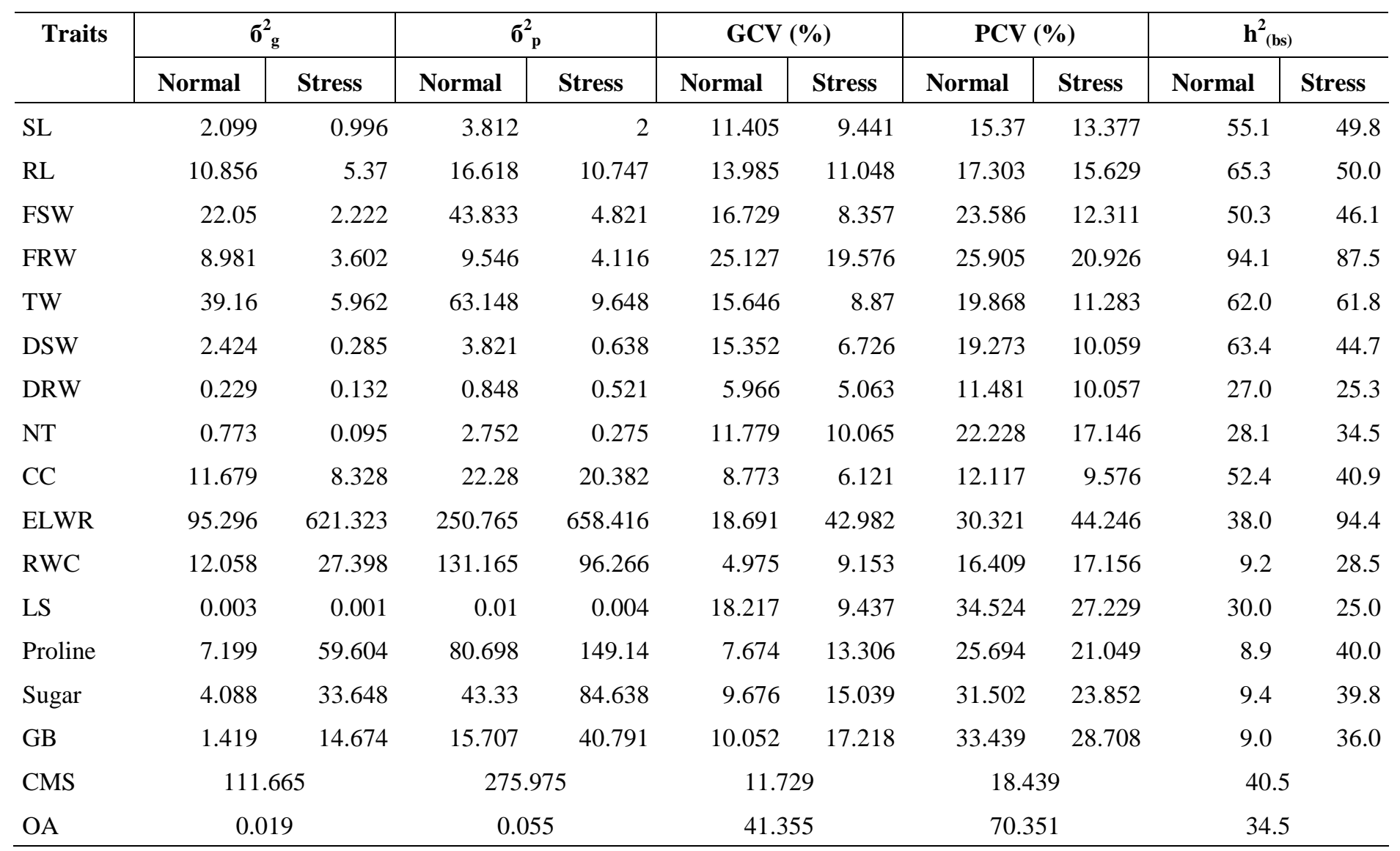

*Phenotypic variance, $\mathrm{GCV}=$ Genotypic coefficient of variation, $\mathrm{PCV}=$ Phenotypic coefficient of variation, $\mathrm{h}^{2}{ }_{(\mathrm{bs})}=$ heritability in broad sense. 